$\mathrm{IJQRM}$

25,5

452

Received October 2007

Revised January 2008

Accepted February 2008

\section{Diffusion of ISO 9000 and ISO 14000 certification in Italian commodity sectors}

\author{
Fiorenzo Franceschini, Maurizio Galetto, Luca Mastrogiacomo \\ and Luciano Viticchiè \\ Politecnico di Torino, Torino, Italy
}

\begin{abstract}
Purpose - ISO 9000 and ISO 14000 standards certification is a phenomenon involving over the years a larger and larger number of companies and organizations. Looking at the empirical data, it is observed that the phenomenon is close to saturation in many countries. In Italy, on the other hand, there is an important increase in the number of certifications. The purpose of this paper is to pick out the different components and aspects which make Italian dynamics so particular.

Design/methodology/approach - In order to do that the single commodity sector was analyzed, studying certifications diffusion in terms of certified sites. With the aim of specializing the analysis within commodity sectors, this information has been compared with the Gross Domestic Product (GDP) percentage expressed by each sector.

Finding - The analysis shows that ISO certifications diffusion followed different dynamics depending on the commodity sectors. These reacted in different ways to the discontinuity of 2003 , the year in which ISO 9000 standards changed from the 1994 to the 2000 version.

Research limitations/implications - Future research efforts will be directed at an in-depth analysis of the differences between ISO 9000 and ISO 14000 certified and analogous non-certified firms. This analysis will be performed using performance indices such as the number of employees, the profitability, the volume of business, etc.

Originality/value - The paper analyzes the dynamic of ISO 9000 and ISO 14000 certification diffusion in Italy in different commodity sectors. The term of comparison is given by the contribution given by each sector to the GDP.
\end{abstract}

Keywords ISO 9000 series, Quality systems, Quality management, Commodity markets, Italy

Paper type Research paper

\section{Introduction}

Currently the interest of public and private companies and organizations for ISO 9000 certification is growing more and more (ISO 9000, 2000; ISO 9000-1, 1994). Although being worldwide spread, ISO certification diffusion is not uniform (Franceschini et al., 2006). In Italy, ISO 9000 and ISO 14000 certification does not seem to suffer any setback (Table I) (ISO, 2001, 2002, 2003, 2004, 2005, 2006). In particular, ISO 9000 certification is swiftly increasing in number reminding Far East countries trend of certification diffusion. Though being more recent, ISO 14000 certification seems to be ready for a similar development trend (ISO, 2001, 2002, 2003, 2004, 2005, 2006).

It is interesting to deeply analyze Italian reality in order to understand whether ISO 9000 and ISO 14000 certification is homogeneously spread in all commodity sectors. The aim of this paper is also to highlight if and how each commodity sector enjoyed benefits from its quality or environment management system. A lot of researchers
International Journal of Quality \& Reliability Management

Vol. 25 No. 5, 2008

pp. $452-465$

(C) Emerald Group Publishing Limited 0265-671X

DOI $10.1108 / 02656710810873862$ 


\begin{tabular}{|c|c|}
\hline ๕ّ̊ & 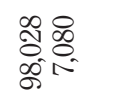 \\
\hline 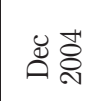 & 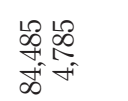 \\
\hline 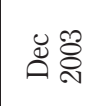 & 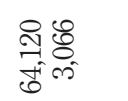 \\
\hline ఊ్రి & 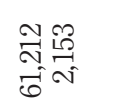 \\
\hline & 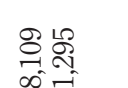 \\
\hline ఊ̊̊ & 應 \\
\hline & \\
\hline 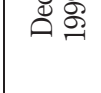 & $\vec{i}$ \\
\hline 莙怘 & $\begin{array}{l}\stackrel{\leftrightarrow}{8} \\
\stackrel{\infty}{\oplus}\end{array}$ \\
\hline 总念 & 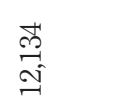 \\
\hline 怘 & 悪 \\
\hline ๕̊g & 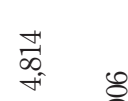 \\
\hline 吾煦 & \\
\hline 总㺃 & 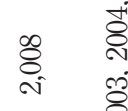 \\
\hline 웡: & त्ञ \\
\hline 통 & 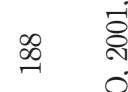 \\
\hline & 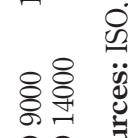 \\
\hline
\end{tabular}

ISO 9000 and ISO 14000 certification

453

Table I. ISO 9000 and ISO 14000 certification in Italy (from January 1993 to December 2004) 
IJQRM

25,5

\section{4}

considered the certification phenomenon in different production contexts, pointing out specific peculiarities: chemical and pharmaceutical sector (Biniecka et al., 2005), oil-petroleum sector (Price, 1999), tourist sector (Chan and Wong, 2006), electronic sector (Quazi et al., 2001), food sector (Boudouropoulos and Arvanitoyannis, 1999), agricultural sector (Wall et al., 2001).

\section{ISO 9000 and ISO 14000 certification in different commodity sectors}

In this section we discuss certification diffusion in Italy focusing on different commodity sectors. The aim is to find out and classify peculiarities distinguishing between different sector behaviors.

Data, split according to EA classification, refer to the period 1999-2005 (Table II) (Sincert, 2006). To this paper purpose, various accreditation sectors are considered as union of possible under-sectors (for instance, sector EA28 includes sectors EA28a and EA28b).

ISO 9000 certified sites

To December 2005, the certified sites percentages for commodity sector went from a 0.04 percent minimum (EA8 - Publishing companies) to a 22.14 percent maximum (EA28 - construction). We excluded sector EA11, which, up to then did not show any certificate. It is clear that each EA sector contribution to ISO 9000 certification differ depending on different market facilities.

In the same year (2005), 22 out of 39 EA classification sectors, had less than the 1 per cent of ISO 9000 certified sites. Among the remaining ones, only sector EA28 had a certified sites percentage larger than 10 percent; the percentage of all the others (17 EA sectors) was included between 1 percent and 10 percent. At the end of December 2005 the top ten industrial sites was the same of the previous years with a few rare exceptions. It is important to highlight that some sectors in the top ten (EA28, EA35, EA37, EA38) involve companies that either belong to or run business with Public Administration. This because ISO 9000 certification is often a requirement to access public contracts (Legge Merloni, 1994).

\section{Growth dynamic of ISO 9000 certified sites}

Certification diffusion changes between commodity sectors also in terms of trend typology. The reaction to 2003 change-over from ISO 9000:1994 to ISO 9000:2000 allows a classification between EA sectors. Analyzing ISO 9000 certified sites number for sector, it is possible to recognize four different typologies of behavior (Table III):

(1) Sectors that followed the national average trend of the ISO 9000 certification. We classify in this category the commodity sectors that in 2003 recorded a certified sites increase within 10 percent compared to certified sites number of 2002. Trend of this kind were comparable to the national average trend. Apart from being such monotonic, these sectors marked a modest increase of the certified sites in 2003. Such rates were similar to the national +3 percent, in opposition to well more sustained growth rates marked in previous and following years.

(2) Sectors in a continuous growth. We classify as "sectors in a continuous growth" all those that, in the reference period, recorded a continuous certified sites number increase and, particularly in 2003, larger than 10 percent compared to 


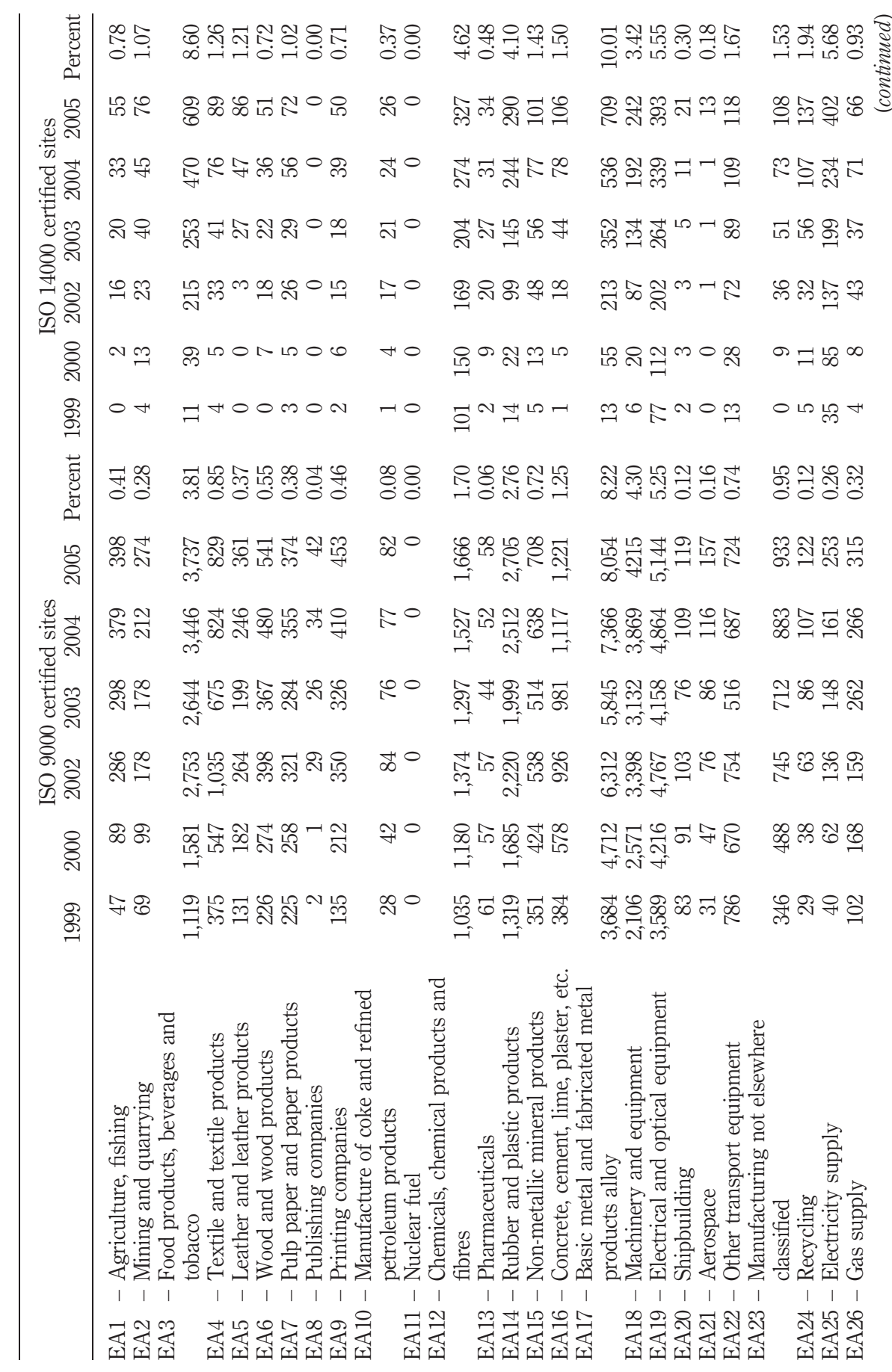

ISO 9000 and ISO 14000 certification

455

Table II.

ISO 9000 and ISO 14000 certified sites in Italy in the period 1999-2005 
IJQRM

25,5

456

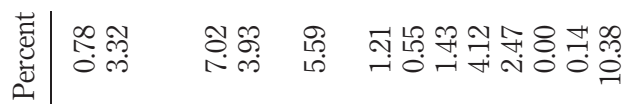

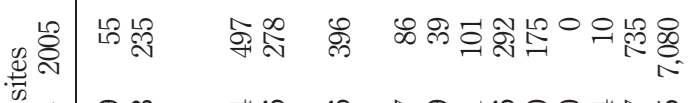

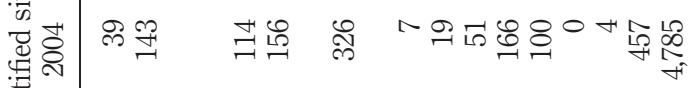

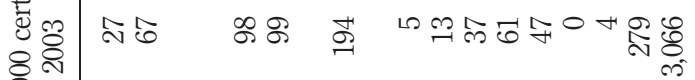



宊

\&

局

苞

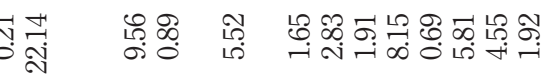

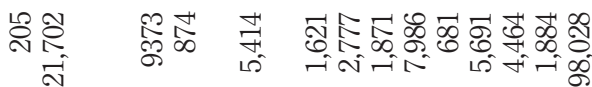

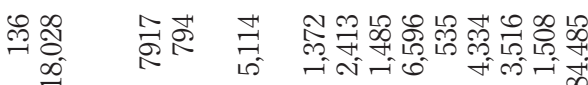

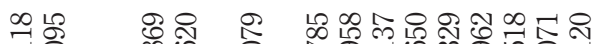

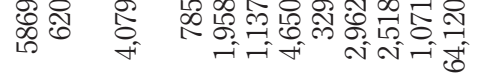

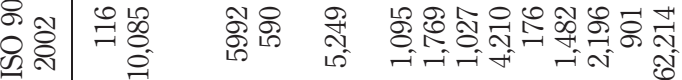

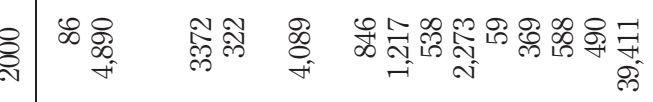



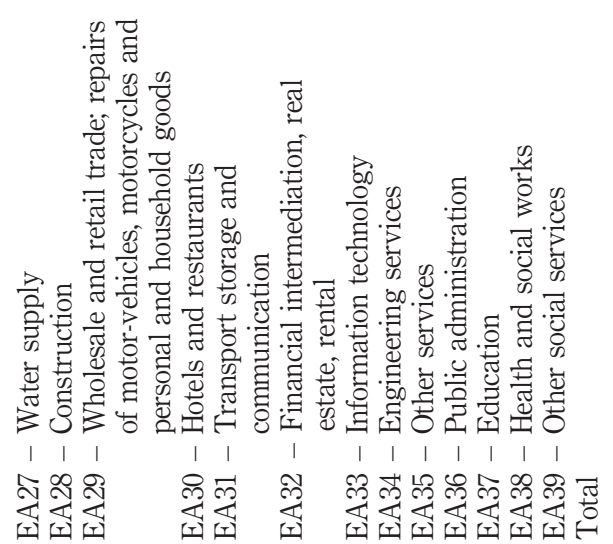

Table II. 
the one of 2002. These sectors did not suffer the change-over of reference standards.

(3) Sectors that suffered 2003 discontinuity and then turned up. In 2003, these sectors recorded a certified sites decrease, while in the following years reached and exceeded such level. Most commodity sectors belong to this category. The transition period from the ISO 9000:1994 to the ISO 9000:2000 certification lasted more than a year.

(4) Sectors with a maximum in 2002. In 2003 these sectors counted a number of certified sites smaller than in 2002. Despite modest positive growth rates from 2004 to 2005, these sectors did not reach the 2003 peak.

ISO 14000 certified sites

The phenomenon of certification according to ISO 14000 standards is younger than the one related to ISO 9000 standards. To December 2005 not all commodity sectors enumerated ISO 14000 certified sites. Sectors EA8 (Publishing companies), EA37 (Education) and EA11 (Nuclear Fuel) did not have any ISO 14000 certified sites. Other EA sectors marked large sites number increases in the last years. Particularly, during 2005, sectors EA21 (Airspace) and EA32 (Financial intermediation, etc.) recorded large increases in the number of ISO 14000 certified sites (respectively $+1,200$ percent and $+1,129$ percent). Such high rates were due to the still low number of certified sites. On the other hand, there were some sectors marking a large number of certified sites, right from 1999. In the following years they continuously increased, but slower than the average growth rate. Sectors EA12, EA17, EA19, EA22, EA25 and EA31 were among these (Table II). This phenomenon did not derive from an endogenous reason to the sector, but rather from other sectors affirmation. Sector EA26 (gas supply) was the only one to show a certified sites maximum in 2004. All the other commodity sectors showed a monotonic increasing trend of the certified sites number, except for EA27 that suffered an initial temporary turndown in 2002.

\section{Comparison between ISO 9000 and ISO 14000 certified sites and potentially certifiable sites}

Certified sites absolute numbers in different commodity sectors are not comparable since they do not refer to the same potentially certifiable sites number. Therefore, we considered the ratio between certified sites and potentially certifiable sites (Franceschini et al., 2004). The aim of this analysis is to operate an EA sector classification. For each sector, information about potentially certifiable sites from 1999 to 2005 have been picked from INFOCAMERE (Camera di Commercio, 2006;

\begin{tabular}{llll}
\hline General trend & Continuous trend & $\begin{array}{l}\text { After the 2003 discontinuity } \\
\text { growth returns }\end{array}$ & Maximum in 2002 \\
\hline EA1, EA2, EA16, EA25, & EA21, EA24, EA26, & EA3, EA5, EA6, EA7, EA8, EA4, EA10, EA22 \\
EA27, EA30 & EA28, EA33, EA34, & EA9, EA12, EA13, EA14, \\
& EA35, EA36, EA37, & EA15, EA17, EA18, EA19, \\
& EA38, EA39 & EA20, EA23, EA29, EA31, \\
& & EA32
\end{tabular}

ISO 9000 and ISO 14000 certification 
$\mathrm{IJQRM}$

25,5

458
Infocamere, 2006). Analyzing data, we observe that potential sites number generally did not change so much. A large part of commodity sectors recorded maximum oscillations contained within 15 percent. For these sectors, to facilitate data comparison among different years, we assumed an average value for the period 1999-2005. As a first approximation we excluded from further analysis those sectors with a high variability of the potentially certifiable sites number. Such variation effects could be confused with the certified sites number variation effects.

\section{ISO 9000 diffusion (certified sites/potential sites) in different Italian commodity sectors}

Table IV shows the ratio between ISO 9000 certified sites and potentially certifiable sites. Data refer to the 31st of December of every year for the period 1999-2005 (data related to 2001 are missing since they have not been published by INFOCAMERE). Taking as a reference the last available year 2005, we observe that sector EA14 (Rubber and plastic products) could boast the highest ISO 9000 diffusion, with almost 16 certified every 100 potentially certifiable sites. Sectors EA12 (Chemicals etc.) and EA13 (Pharmaceuticals) had more than 15 certified out of 100 potentially certifiable sites. From the third up to the last sector for ISO 9000 diffusion, recorded percentages went from around 7 percent to less than the 1 percent.

Sector EA1 (Agriculture and Fishing) marked the lowest ISO 9000 diffusion at the end of 2005 with one certified site out of 2500 potential sites.

Among the EA sectors excluded by this analysis because of the presence of high variations of potentially certifiable sites number, there is a sector (EA37 - Education) whose ISO 9000 certified sites at the end of 2005 were around one out of four

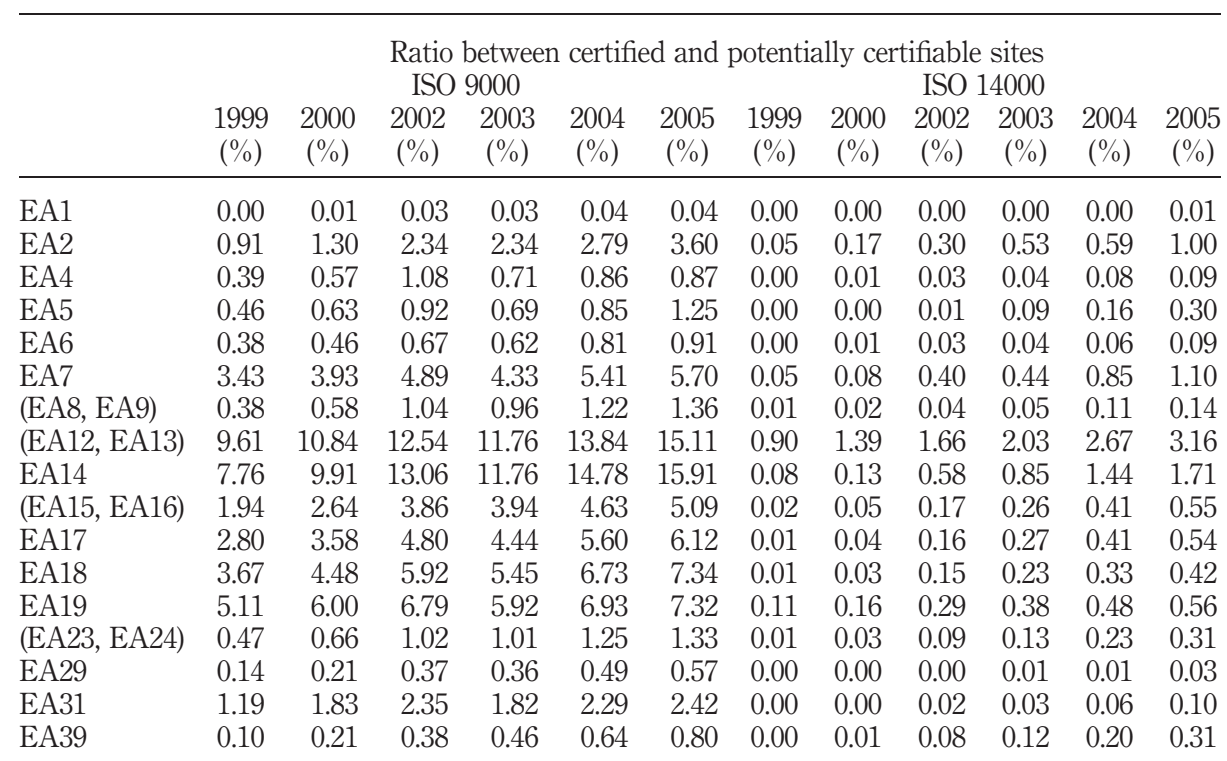

Sources: ISO,2001-2006; Camera di Commercio, 2006; Infocamere, 2006
Table IV.

Ratio between ISO 9000 and ISO 14000 certified sites and the average potentially certifiable sites number in the same sector 
potentially certifiable sites. This sector did not suffer 2003 discontinuity, marking a continuous and sustained certification growth.

ISO 14000 diffusion in different Italian commodity sectors

Analogous studies have been conducted for ISO 14000 diffusion (see Table IV). From 1999 to 2005, the large majority of commodity sectors counted less than one ISO 14000 certified site out of 100 potentially certifiable sites. Exceptions were sectors EA12 and EA13 after the year 2000, EA14 after 2004 and EA2 and EA7 sectors after 2005. During 2005, we observe that the union of the sectors EA12 and EA13 could boast the largest ISO 14000 diffusion, with 3.16 certified sites out of 100 . Not quoted sectors had a number of certified sites that varies between about one out of 200 and one out of 10,000 .

\section{Combined analysis of the certification diffusion and the value added to the GDP}

It is interesting to know how different commodity sectors took advantage of certification diffusion, and if such an advantage is proportional to the certified sites percentage. To measure such "benefits" one of the most appropriate key indicator is the commodity sectors contribution to the national GDP (the value added). The analyzed hypothesis is that sectors that draw higher benefits from certification produce higher margin and therefore higher value added. This standing all other factors influencing wealth creation. Once estimated certification diffusion trend and GDP percentage, we made a classification of various EA sectors through special diagrams.

Diagrams "certified sites versus contribution to GDP"

We traced trends of EA sectors with slight potential sites variations. From a first analysis of such trends, it is possible to classify commodity sectors in four categories:

(1) Proportional growth - Concurrent increase of certification diffusion and incidence on GDP. As a first approximation, such trends are characterized by linearly distributed points (Figure 1a).

(2) Static - Lack of sensible variations in both the variables (Figure 1b).

(3) Vertical - Increase of certification diffusion without increase of GDP incidence, trends nearly linear and parallel to the ordinates (Figure 1c).

(4) Horizontal - Increase on the GDP without substantial certification diffusion increase, trends nearly parallel to the abscissas (Figure 1d).

"Certified sites versus contribution to GDP" diagrams are shown in Figures 2-5. They respectively refer to ISO 9000 and ISO 14000 certification.

Diagrams analysis and classification

Figure 2 offers a pattern of different commodity sectors trends. We highlight quoted sectors EA14 and EA12-EA13 for the remarkable growth of the certified sites percentage.

Figure 2 shows that these sectors did not draw any benefits from certification (in terms of GDP). Obviously, it does not mean that the single ISO 9000 certified enterprise did not draw any benefits. For instance, it could be grown at uncertified competitor's expense. On the other hand, sectors EA31 (Transport and storage) and EA29
ISO 9000 and ISO 14000 certification 
IJQRM

25,5

460

Figure 1.

Trends classification on the diagram

Figure 2.

Trend of ISO 9000 certification diffusion versus GDP contribution for various commodity sectors in the period 1999-2005



(a)

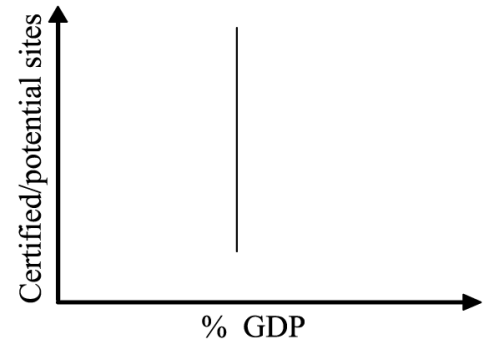

(c)



(b)

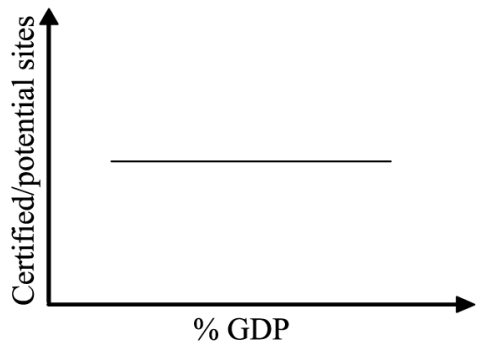

(d)
Notes: (a) Proportional Growth - correlation between certification diffusion and GDP percentage, (b) Static - lack of significant variations on both variables, (c) Vertical certification diffusion increase without GDP percentage increase, (d) Horizontal - GDP percentage increase without increase of certified sites percentage.

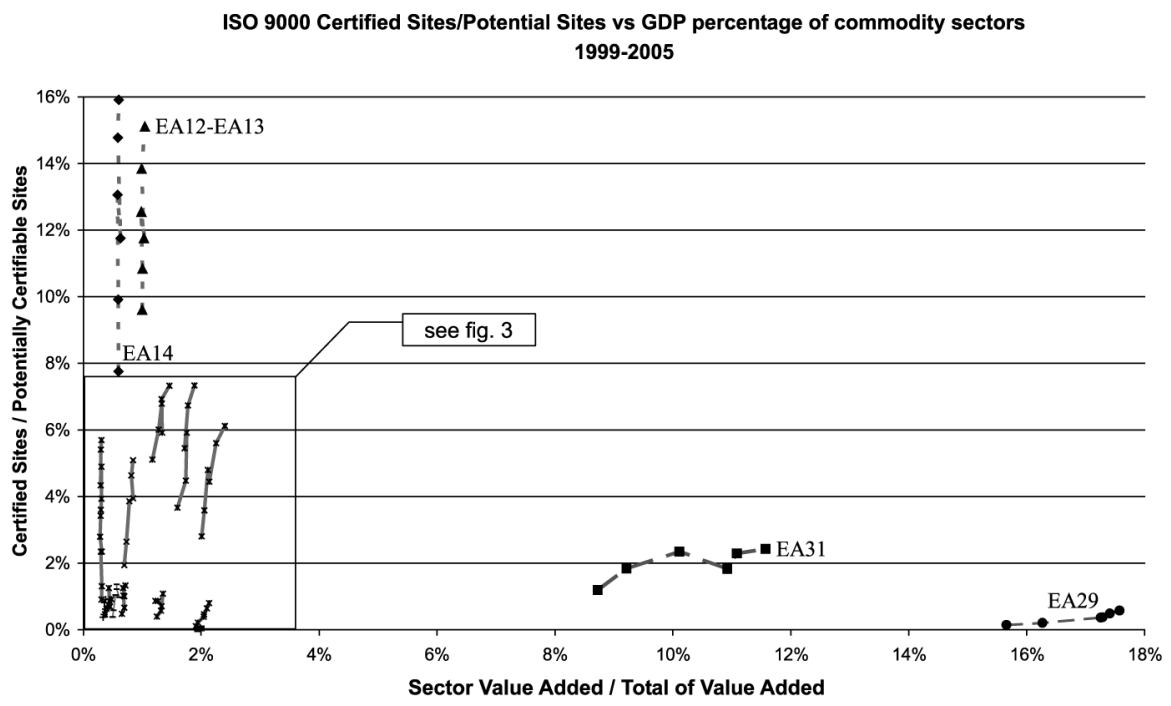

Sources: ISO (2001-2006), Camera di Commercio (2006), Infocamere (2006) 


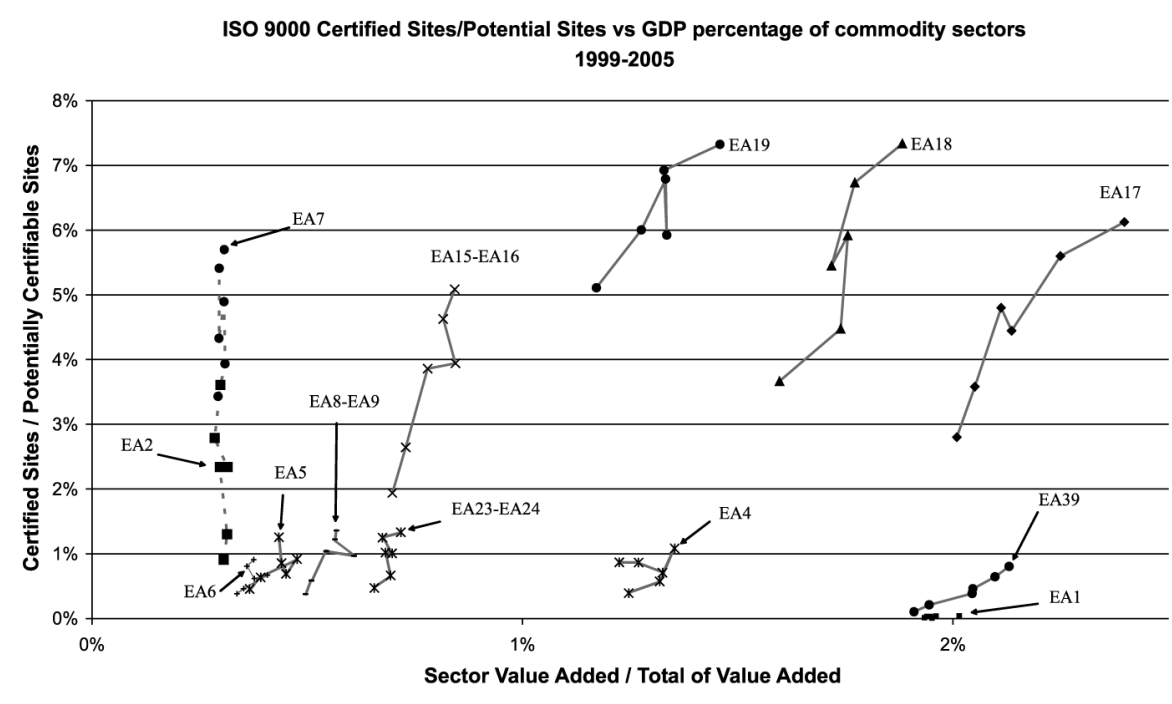

Sources: ISO (2001-2006), Camera di Commercio (2006), Infocamere (2006)

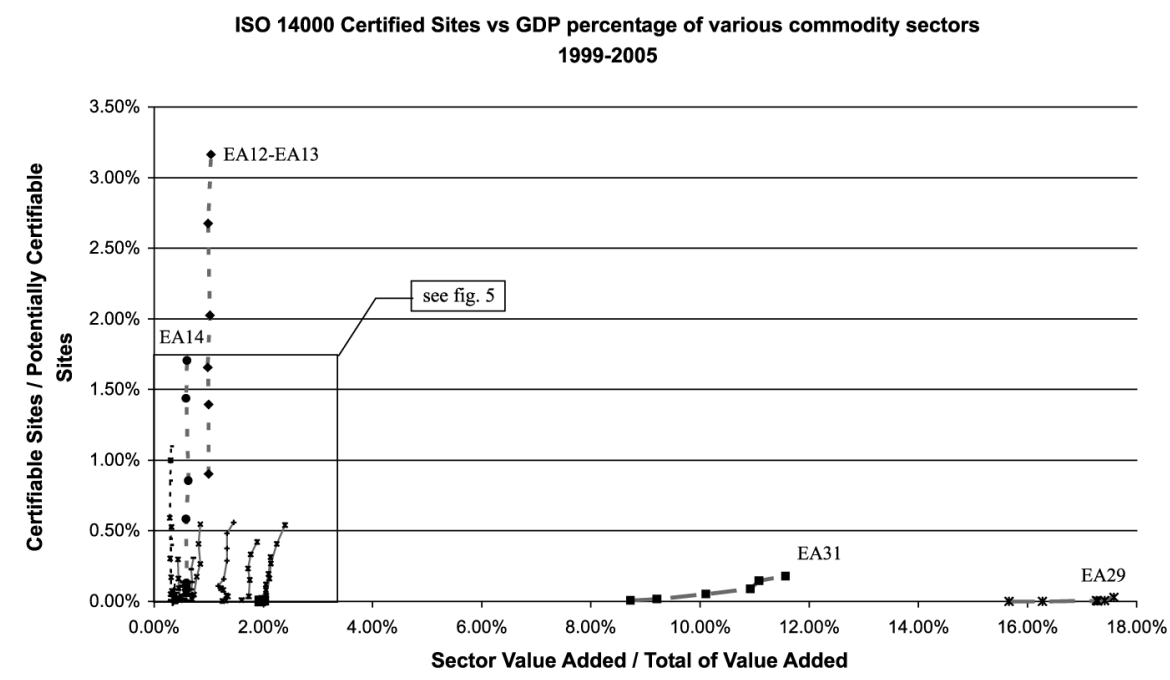

Sources: ISO (2001-2006), Camera di Commercio (2006), Infocamere (2006)
ISO 9000 and ISO 14000 certification 461

Figure 3.

Particular (see Figure 2) of the ISO 9000 certification diffusion trends and of the GDP contribution from various sectors in the period 1999-2005
Figure 4. Trend of ISO 14000 certification diffusion versus GDP contribution for various commodity sectors in the period 1999-2005

(Wholesale etc.) respectively went from expressing few more than 8 percent of GDP to almost 12 percent and from few less than 16 percent to almost 18 percent. This without recording meaningful certified sites percentage growths (2 percent for sector EA31 and less than the 1 percent for sector EA29). Therefore, such sectors growth does not seem due to the related ISO 9000 sites certification. 
IJQRM

25,5

462

Figure 5.

Particular of ISO 14000 diffusion trends and of GDP contribution from various sectors in the period 1999-2005

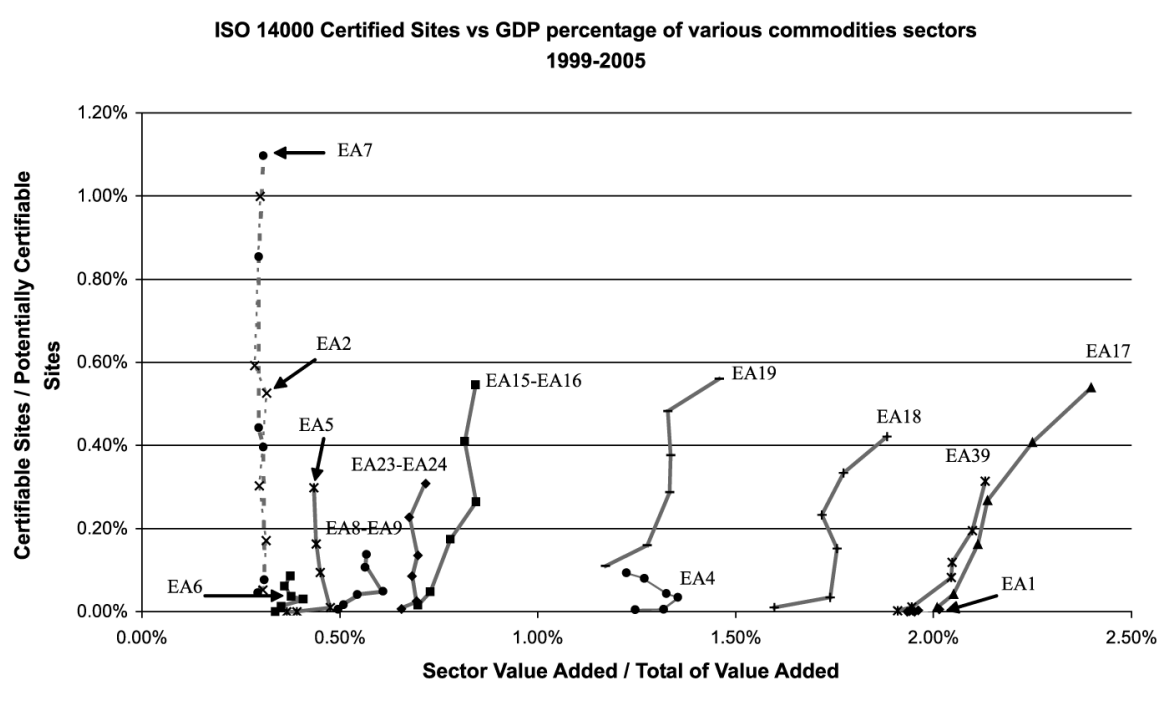

Sources: ISO (2001-2006), Camera di Commercio (2006), Infocamere (2006)

Figure 3 proposes a detail of Figure 2. Trends of sectors EA2 and EA7 were comparable to the one of sectors EA14 and EA12-EA13, while no sector had a trend similar to those recorded by EA29 and by EA31. Remaining sectors described two other trends typologies: proportional or static. Among the first ones we signal sectors EA17, EA18 and EA19. Beside the growth of ISO 9000 certified sites percentage they recorded an increase in the GDP percentage of at least half a point. Sectors EA15-EA16 and EA39 followed an analogous trend with more contained variations. For them it is possible to hypothesize a correlation among the considered variables. Further studies could verify the existence of a relation of a functional dependency. Remaining EA sectors registered a static trend (cloud of assembled points), suggesting that the two variables did not mark meaningful variations during this time period.

We evaluated the correlation among the two variables for all EA sectors. Results are shown in Table V. For all sectors classified with the proportional growth trend, we calculated a correlation coefficient at least equal to 0.89 . Lower values characterize static sectors trends. Sectors with trend classified as vertical may sometimes have negative coefficients, in any case low in absolute value. For sectors with horizontal trend, the correlation is always low.

Table V.

Classification of EA sectors according to the variation of ISO 9000 diffusion vs the incidence variation on GDP

\begin{tabular}{llll}
\hline Proportional & Static & Vertical & Horizontal \\
\hline EA15-EA16(0.92), & EA1(0.59), EA4(0.33), & EA2(-0.53), EA7(0.31), & EA29(0.93), \\
EA17(0.94), EA18(0.90), & EA5(0.61), EA6(0.51), & EA12-EA13(0.32), & EA31(0.78) \\
EA19(0.89), EA39(0.98). & EA8-EA9(0.74), & EA14(-0.09) & \\
& EA23-EA24(0.6). & & \\
\hline
\end{tabular}


Combined analysis among the ISO 14000 certification diffusion and the value added to GDP Similar analyses have been conducted for ISO 14000 certification. Figure 5 proposes a detail of Figure 4. Also for ISO 14000 certification it is possible to classify EA sectors according to trends in terms of certification diffusion and contribution to the GDP. ISO 9000 and ISO 14000 trends are quite the same (see Table VI). Nevertheless ordinates values of ISO 14000 trends are noticeably inferior in comparison to those of ISO 9000 certification.

\section{Conclusions}

ISO 9000 certification analysis sorted out deep differences among various commodity sectors in Italy. Sectors of Public Administration, and those that have strong contractual relationships with, recorded the highest absolute number of ISO 9000 certified sites. One of the reasons that can explain this phenomenon is the demand for ISO 9000 certification by law. These sectors did not suffer any 2003 discontinuity. Other EA sector differently reacted to such discontinuity, from the time trend analysis of ISO 9000 certified sites; we classified them in four categories.

ISO 14000 certified sites are continuously increasing in all commodity sector with a few rare exceptions, even if ISO 14000 standards generally recorded a more modest diffusion than ISO 9000 standards. To December 2005, less than one site out of 100 was certified according to ISO 14000 standards on average.

For both ISO 9000 and ISO 14000 standards, the certified sites number has been evaluated considering the potentially certifiable sites number for each commodity sector. From this analysis deep differences emerged among EA sectors. Analyzing correlation between certified sites percentage and contribution to GDP, it has been possible to recognize four trend typologies:

(1) proportional growth;

(2) static;

(3) vertical; and

(4) horizontal.

A first result connected to such classification is the detection of substantial differences in the reaction of EA sectors to the ISO 9000 and ISO 14000 certification phenomenon.

Future analyses will concern the comparison, in terms of business volume, employee number, profit, etc., between certified sites and uncertified sites from the same sector.

\begin{tabular}{llll}
\hline & & & \\
Direct ratio & $\begin{array}{l}\text { GDP \% - Invariant Cert. } \\
\text { Sites \% }\end{array}$ & $\begin{array}{l}\text { Invariant GDP \% - Cert. } \\
\text { Sites \% Increase }\end{array}$ & $\begin{array}{l}\text { Sites } \% \text { - GDP \% } \\
\text { Increase }\end{array}$ \\
\hline EA15-EA16(0.87) & EA4(-0.43), EA5(0.30), & EA2(-0.39), EA7(0.12), & EA29(0.63), \\
EA17(0.98), EA18(0.82), & EA6(0.38), & EA12-EA13(0.47), & EA31(0.95) \\
EA19(0.89), EA39(0.93) & EA8-EA9(0.58), & EA14(0.12) & \\
& EA23-EA24(0.62) & &
\end{tabular}

ISO 9000 and ISO 14000 certification

463 
IJQRM

25,5

464

\section{References}

Biniecka, M., Campana, I. and Iannilli, I. (2005), "The technological and economic management of the environmental variable in the pharmaceutical-chemical industry", Microchemical Journal, Vol. 79 Nos 1/2, pp. 325-9.

Boudouropoulos, I.D. and Arvanitoyannis, I.S. (1999), "Current state and advances in the implementation of ISO 14000 by the food industry. Comparison of ISO 14000 to ISO 9000 to other environmental programs", Trend in Food Science \& Technology, Vol. 9 Nos 11/12, pp. 395-408.

Camera di Commercio (2006), Official Italian Chamber of Commerce web sites, available at: www. cameradicommercio.it (accessed April 2006).

Chan, E.S.W. and Wong, S.C.K. (2006), "Motivations for ISO 14001 in the hotel industry", Tourism Management, Vol. 27 No. 3, pp. 481-92.

Franceschini, F., Galetto, M. and Cecconi, P. (2006), “A worldwide analysis of ISO 9000 standard diffusion: considerations and future development”, Benchmarking: An International Journal, Vol. 13 No. 4, pp. 523-41.

Franceschini, F., Galetto, M. and Gianni, G. (2004), "A new forecasting model for the diffusion of ISO 9000 Standard Certifications in European countries”, International Journal of Quality \& Reliability Management, Vol. 21 No. 1, pp. 32-50.

Infocamere (2006), available at: www.infocamere.it (accessed April 2006).

ISO 9000 (2000), Quality Management Systems - Fundamentals and Vocabulary, ISO, Geneva.

ISO 9000-1 (1994), Quality Management and Quality Assurance Standards - Part 1: Guidelines for Selection and Use, ISO, Geneva.

ISO (2001), The ISO Survey of ISO 9000 and ISO 14000 Certificates. Tenth Cycle, 2000, ISO, Geneva.

ISO (2002), The ISO Survey of ISO 9000 and ISO 14000 Certificates. Eleventh Cycle, 2001, ISO, Geneva.

ISO (2003), The ISO Survey of ISO 9000 and ISO 14000 Certificates. Twelfth Cycle, 2002, ISO, Geneva.

ISO (2004), The ISO Survey of ISO 9000 and ISO 14000 Certificates. Thirteenth Cycle, 2003, ISO, Geneva.

ISO (2005), The ISO Survey of ISO 9000 and ISO 14000 Certificates. Fourteenth Cycle, 2004, ISO, Geneva.

ISO (2006), The ISO Survey of ISO 9000 and ISO 14000 Certificates, Fifteenth Cycle, 2005, ISO, Geneva.

Istat (2006), available at: www.istat.it

Legge Merloni (1994), "Legge quadro in materia di lavori pubblici", Gazzetta Ufficiale della Repubblica Italiana, No. 41.

Price, B.J. (1999), "Effective responses to public reviews: an environmental manager's perspective at Phillips Petroleum companies", Corporate Environmental Strategy, Vol. 6 No. 1, pp. 78-82.

Quazi, H.A., Khoo, Y-K., Tan, C-M. and Wong, P.-S. (2001), "Motivation for ISO 14000 certification: development of a predictive model", The International Journal of Management Science, Omega, Vol. 29 No. 6, pp. 525-42.

Sincert (2006), "Database query on official Sincert website", available at: www.sincert.it.

Wall, E., Weersink, A. and Swanton, C. (2001), “Agriculture and ISO 14000”, Food Policy, Vol. 26 No. 1, pp. 35-48. 


\section{About the authors}

Fiorenzo Franceschini is Professor of Quality Management in the Department of Production Systems and Business Economics at Politecnico di Torino, Torino, Italy. Fiorenzo Franceschini is the corresponding author and can be contacted at: fiorenzo.franceschini@polito.it

Maurizio Galetto is an Assistant Professor in the Department of Production Systems and Business Economics at Politecnico di Torino, Torino, Italy.

Luca Mastrogiacomo is a $\mathrm{PhD}$ student in the Department of Production Systems and Business Economics at Politecnico di Torino, Torino, Italy.

Luciano Viticchiè is a PhD student in the Department of Production Systems and Business Economics at Politecnico di Torino, Torino, Italy.
ISO 9000 and ISO 14000 certification 465

To purchase reprints of this article please e-mail: reprints@emeraldinsight.com Or visit our web site for further details: www.emeraldinsight.com/reprints 